\title{
FURTHER OBSERVATIONS ON THE OCCURRENCE OF RHEU- MATIC MANIFESTATIONS IN THE FAMILIES OF RHEUMATIC PATIENTS
}

\author{
By ROSS L. GAULD, ANTONIO CIOCCO, AND FRANCES E. M. READ ${ }^{1}$ \\ (From the Cardiac Clinic of the Harriet Lane Home (Department of Pediatrics) of the Johns \\ Hopkins Hospital in cooperation with Child Hygiene Investigations of the United States \\ Public Health Service and the Departments of Epidemiology and Biology, Johns \\ Hopkins University, School of Hygiene and Public Health, Baltimore)
}

(Received for publication November 23, 1938)

In a previous paper (1) the frequency of rheumatic manifestations was shown to be significantly higher among the near relatives of a series of children affected with rheumatic disease than among the corresponding relatives of a control series of non-rheumatic children. The findings were not conclusive, but did suggest that inherited predisposition may be an important factor in the development of the disease, and indicated the need for further investigation. The purpose of this article is to present additional facts bearing on this subject.

\section{MATERIAL AND METHODS}

The data upon which this report is based consist of the medical histories of 96 consecutive admissions of white children to the Cardiac Clinic of the Harriet Lane Home because of some rheumatic manifestation, and of 33 white children examined in the Tuberculosis Clinic of the Harriet Lane Home. The histories include a careful epidemiological study of the immediate families of these children, and the families of their parents, so that accurate information is available regarding the rheumatic history of the patients and their siblings, parents, grandparents, uncles, and aunts.

The children admitted to the clinics, and who are responsible for the inclusion of their respective families in the study, are denominated "index cases" to distinguish them from their relatives who enter the study because of their relationship to these cases.

In this paper, as in the preceding one, a rheumatic manifestation is defined as either chorea, rheumatic fever, or rheumatic carditis. All index

\footnotetext{
1 Acknowledgment is made by the authors of the inspiration and advice of the late Dr. W. H. Frost who guided the early stages of this study.
}

cases of the rheumatic group entered the clinic because they were suffering from one or more of these conditions. The index cases who were children examined in the Tuberculosis Clinic, and their relatives, are used as a control group and none of the index cases in this group has had an acute rheumatic episode.

The selection of the material, verification of the information, and comparability of the two groups were discussed fully in the previous article, which dealt with a smaller group of rheumatic families than is here analyzed. It should be emphasized again that the two groups of families are comparable for such factors as age, mortality, and social and economic status.

\section{The ancestry of rheumatic and control children}

A comparison of the rheumatic and control index cases, with respect to the history of rheumatic manifestations in their parents and grandparents, is presented in detail in Table I. This table shows the various parental and grandparental mating combinations with respect to the occurrence of rheumatic disease, and the number of index cases in both the rheumatic and control series for each combination. This table may be summarized as follows :

\begin{tabular}{|c|c|c|c|}
\hline \multicolumn{2}{|l|}{ Number of index cases } & Rheumatic & Control \\
\hline $\begin{array}{l}\text { With parental histories } \\
\text { complete } \\
\text { With rheumatic history in } \\
\text { parents }\end{array}$ & $\begin{array}{l}\text { Number } \\
\text { Per cent }\end{array}$ & $\begin{array}{c}96 \\
43 \\
44.8\end{array}$ & $\begin{array}{r}33 \\
4 \\
12.1\end{array}$ \\
\hline $\begin{array}{l}\text { With grandparental his- } \\
\text { tories complete } \\
\text { With rheumatic history in } \\
\text { grandparents }\end{array}$ & $\begin{array}{l}\text { Number } \\
\text { Per cent }\end{array}$ & $\begin{array}{c}86 \\
49 \\
57.0\end{array}$ & $\begin{array}{r}32 \\
4 \\
12.5\end{array}$ \\
\hline $\begin{array}{l}\text { With complete parental } \\
\text { and grandparental his- } \\
\text { tories } \\
\text { With rheumatic history in } \\
\text { parents or grandparents }\end{array}$ & $\begin{array}{l}\text { Number } \\
\text { Per cent }\end{array}$ & $\begin{array}{c}86 \\
63 \\
73.3\end{array}$ & $\begin{array}{c}32 \\
7 \\
21.9\end{array}$ \\
\hline
\end{tabular}


TABLE I

Distribution of index cases of rheumatic and control families according to the correlation of the history of rhematic manifestations in the parents and grandparents*

\begin{tabular}{|c|c|c|c|c|c|c|c|c|c|c|c|c|c|}
\hline \multicolumn{4}{|c|}{ Grandparental history } & \multirow{2}{*}{\multicolumn{5}{|c|}{$\frac{\text { Rheumatic index cases }}{\text { Parental history }}$}} & \multirow{2}{*}{\multicolumn{5}{|c|}{$\frac{\text { Control index cases }}{\text { Parental history }}$}} \\
\hline \multicolumn{2}{|c|}{ Paternal } & \multicolumn{2}{|c|}{ Maternal } & & & & & & & & & & \\
\hline GF & GM & GF & GM & $\underline{\mathbf{F}} \mathbf{M}$ & $\stackrel{\mathbf{F}}{+} \stackrel{\mathbf{M}}{-}$ & $\underline{\mathbf{F}} \stackrel{\mathbf{M}}{+}$ & $\begin{array}{r}\mathbf{F} \\
+\stackrel{\mathbf{M}}{+} \\
\end{array}$ & Total & $\underline{\mathbf{F}} \mathbf{M}$ & $\begin{array}{l}\mathbf{F} \\
+\end{array}$ & $\underline{\mathbf{F}} \stackrel{\mathbf{M}}{+}$ & $\begin{array}{l}\mathbf{F} \mathbf{M} \\
+\quad+ \\
\end{array}$ & Total \\
\hline $\begin{array}{l}\bar{z} \\
\bar{z} \\
\bar{t} \\
\pm \\
\pm \\
\pm \\
\pm \\
\overline{-} \\
\overline{-} \\
\overline{-} \\
\overline{+} \\
+ \\
+ \\
+ \\
? \\
? \\
? \\
? \\
? \\
? \\
-\end{array}$ & $\begin{array}{l}\bar{z} \\
\bar{z} \\
\bar{z} \\
\bar{z} \\
\bar{z} \\
\overline{ \pm} \\
\pm \\
\pm \\
\pm \\
+ \\
+ \\
+ \\
\pm \\
\pm \\
\bar{z} \\
\overline{-} \\
\bar{?} \\
? \\
-\end{array}$ & 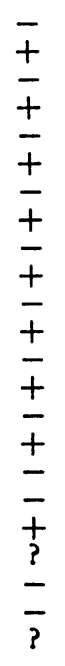 & $\begin{array}{l}\overline{-} \\
\bar{t} \\
\pm \\
\pm \\
\bar{t} \\
\pm \\
\pm \\
\overline{+} \\
\bar{t} \\
\pm \\
\pm \\
\overline{+} \\
\pm \\
\pm \\
+ \\
+ \\
\pm \\
\bar{t} \\
\bar{t} \\
?\end{array}$ & $\begin{array}{l}4 \\
1 \\
\\
1 \\
1 \\
1 \\
1 \\
2\end{array}$ & $\begin{array}{l}3 \\
1 \\
2 \\
1\end{array}$ & $\begin{array}{l}9 \\
6 \\
2 \\
1 \\
1 \\
2 \\
1\end{array}$ & $\begin{array}{l}2 \\
2 \\
2\end{array}$ & $\begin{array}{r}37 \\
12 \\
11 \\
4 \\
9 \\
1 \\
8 \\
8 \\
1 \\
2\end{array}$ & $\begin{array}{r}25 \\
2 \\
\\
1 \\
1\end{array}$ & 3 & 1 & & $\begin{array}{r}28 \\
2\end{array}$ \\
\hline \multicolumn{4}{|c|}{ Total. } & 53 & 9 & 27 & 7 & 96 & 29 & 3 & 1 & & 33 \\
\hline
\end{tabular}

* $F=$ father. $M=$ mother. $G F=$ grandfather. $G M=$ grandmother.

It was possible to obtain complete histories with respect to the occurrence of rheumatic manifestations on every parent of all the rheumatic and control index cases, but the history with respect to rheumatic disease is complete in the grandparents of only 86 of the rheumatic and 32 of the control index cases. The discussion, therefore, of the proportion of index cases with history of rheumatic manifestations in their grandparents is limited to those cases for whom the information was complete.

Of the 96 rheumatic index cases, 43 , or 44.8 per cent, had one or both parents with a history of rheumatic disease in the past as compared with 4, or 12.1 per cent, of the 33 control index cases. Thus the percentage of index cases with rheumatic parents in the rheumatic group was 3.7 times as high as that of the control group. The percentage of index cases who had grandparents with a positive history in the rheumatic group was almost five times that found in the control group, the percentages being 57.0 to 12.5 .
When both parental and grandparental histories are considered, the percentage of index cases with at least one parent or grandparent giving a history of rheumatic manifestations was 73.3 per cent in the rheumatic group as compared with 21.9 per cent in the control group. These results show quite definitely that a much greater proportion of the rheumatic index cases have parents or grandparents who have had rheumatic disease than is found in the corresponding relatives of the control index cases. They demonstrate in another form the findings of the previous article, which showed that there was an unusual occurrence of this disease in the families of rheumatic index cases.

The findings with respect to the percentage of rheumatics who have parents with rheumatic histories is, moreover, consistent in the two generations analyzed. Forty-three of the 96 rheumatic index cases had parents with a history of rheumatic disease. A study of Table I shows that 36 of these had one parent rheumatic and 7 had 
both parents rheumatic, or there were in all 50 rheumatic parents. A summary of the history of rheumatic manifestations in their parents (grandparents of the index cases) compiled from Table I shows for these rheumatic parents:

Number of rheumatic parents of index cases with rheumatic history in their parents Number

Per cent 46.0

This percentage is in agreement with the percentage of index cases whose parents gave a history of rheumatic manifestations seen in the summary of Table I, and shows the consistency of this finding in two generations of these rheumatic families.

\section{The offspring of rheumatic and non-rheumatic parents}

The families in this study were selected in two ways, (1), those of the rheumatic index cases because at least one child, the index case, came to the clinic with some form of rheumatic manifestation, and (2), those of the control group because the index case was examined in the Tuberculosis Clinic and had not had an acute rheumatic episode. Thus, by definition, at least one child in each of the rheumatic families must be rheumatic, and one child in each of the control families must be non-rheumatic. ${ }^{2}$ Because of this method of selection, the immediate families of the index cases are not suitable for a direct comparison of the relative frequency of rheumatic infection in the offspring of the parental matings.

The information obtained for the grandparents and their children may, however, be used for this purpose, because selection of the families was entirely independent of any prior knowledge of the past history with respect to rheumatic manifestations of the grandparents, parents, uncles, or aunts of the index cases. The findings of this analysis are, therefore, not comparable with the findings of other investigators who used the immediate families of their index cases to study this relation $(2,3,4)$.

2 It should be noted that control families were selected without reference to the past history of rheumatic manifestations in the siblings of the index case so that it could happen that some of the siblings had been registered in the Cardiac Clinic-this did occur in three instances.
These grandparental families also have the advantage in that they are complete; the grandparents are all past the reproductive age and their living offspring are mostly past the age of maximum incidence of rheumatic disease. It is also permissible to combine data on both the rheumatic and control families, because in this generation any difference which might be shown between the two groups is not due to the method of sampling but should rather be considered due to the selectivity of the disease.

The total number of grandparental families in the combined rheumatic and control groups was 258 , and complete information was available with respect to the history of rheumatic manifestations in the parents and children of 246 of these families (see Table I). From the 246 matings, for which complete histories are available, there are 1303 offspring, of which 150 had a history of some type of rheumatic manifestation.

The distribution of the grandparents of index cases according to their history of rheumatic disease, the number of offspring, and the number and percentage of rheumatic offspring from each type of mating is shown, by sex, in Table II.

TABLE II

Distribution of grandparental families of index cases according to the history of rheumatic disease in the parents, with the number of offspring of each type of mating, and the number and percentage of theumatic offspring, by sex

\begin{tabular}{c|c|c|c|c|c|c}
\hline \hline & \multicolumn{3}{|c|}{ History of rheumatic manifestations in parents of } \\
grandparental families (Brandparents of index cases)
\end{tabular}

A study of this table shows that where one or both parents (grandparents of index cases) gave a rheumatic history a much higher percentage of the offspring (parents, uncles, and aunts of index cases) were affected than when neither mate had manifestations. There are, in addition, some interesting sex differences which are worthy of note. From the 34 matings of a rheumatic female with a non-rheumatic male there were 104 female off- 
spring of whom 34 were affected, and 85 male offspring of whom 16 had manifestations. Rheumatic mothers thus had almost twice the percentage of rheumatic children among their female offspring than they had among their male offspring. This is in contrast to the fact that no difference is noted in the percentage of male and female offspring who were rheumatic in the 24 families where the father was rheumatic and the mother non-rheumatic. Viewed from another angle, we note with respect to the male offspring, that there was apparently no difference in the percentage who were rheumatic in the families in which the mother gave a positive history and those in which the father gave a positive history. Such was not the case with the female offspring, the percentage of female offspring who were rheumatic being almost twice as high in the families where the mother was rheumatic as it was in the families of rheumatic fathers.

The higher percentage of rheumatic children found among the offspring of rheumatic parents than among the offspring of non-rheumatic parents suggests that the hereditary constitution may be a factor in determining predisposition to this disease. The higher frequency of rheumatic disease among female offspring of rheumatic mothers would seem to indicate that if heredity is a factor a sex difference exists.

\section{Rheumatic manifestations on the paternal and maternal sides of families of rheu- matic index cases}

A comparison of the percentage of the offspring of the paternal and maternal grandparents of the rheumatic index cases who gave a history of rheumatic manifestations yields further information upon possible hereditary relationships. In making such a comparison, the parents of the index cases must be excluded, because by the method of selection of these families, there must be one male child in each family of paternal grandparents and one female child in each family of maternal grandparents. Any hereditary factor present in these families would also manifest itself most strongly in the parents of the rheumatic index cases since if such a factor be present, they must, of necessity, be the transmitters of the disease.

Another consideration is the accuracy of the histories obtained, because it is generally much easier to interview the mother than the father of the index case, and for this reason only those families on the paternal side were considered in which the history of rheumatic disease was obtained from the father or one of his sisters.

The histories of 86 paternal and 96 maternal families are believed to be accurate, and these have been analyzed to show the percentage of aunts and uncles (siblings of parents of index case) with a rheumatic history on the paternal as compared with the maternal side. This comparison is shown in Table III.

TABLE III

Comparison of the relative frequency of rheumatic manifestations in the aunts and uncles of rheumatic index cases on the paternal and maternal sides

\begin{tabular}{|c|c|c|c|c|c|c|}
\hline \multirow{3}{*}{$\begin{array}{l}\text { Relation } \\
\text { to index } \\
\text { case }\end{array}$} & \multicolumn{3}{|c|}{ Paternal } & \multicolumn{3}{|c|}{ Maternal } \\
\hline & \multirow{2}{*}{ Number } & \multicolumn{2}{|c|}{ Rheumatic } & \multirow{2}{*}{ Number } & \multicolumn{2}{|c|}{ Rheumatic } \\
\hline & & Number & Per cent & & Number & Per cent \\
\hline $\begin{array}{l}\text { Uncles . . } \\
\text { Aunts. . }\end{array}$ & $\begin{array}{l}159 \\
172\end{array}$ & $\begin{array}{l}4 \\
9\end{array}$ & $\begin{array}{l}2.5 \\
5.2\end{array}$ & $\begin{array}{l}213 \\
225\end{array}$ & $\begin{array}{l}33 \\
35\end{array}$ & $\begin{array}{l}15.5 \\
15.6\end{array}$ \\
\hline
\end{tabular}

A study of this table reveals the interesting fact that while there is no difference between the proportion of the uncles and aunts who have rheumatic manifestations on their respective sides of the family, the percentage of maternal aunts and uncles who had rheumatic manifestations is almost three times that of the paternal aunts and uncles.

As these aunts and uncles enter the study because they are siblings of the parents of the index cases, any interpretation of the above finding is dependent to some extent upon whether the difference noted is due to the fact that in this group of families a greater number of mothers than fathers of index cases had a history of having had rheumatic disease (see Table I). A further analysis has therefore been made in which the aunts and uncles are classified as siblings of rheumatic and non-rheumatic parents to compare paternal and maternal sides of these families according to the history of the parent through whom they are related to the rheumatic index case. This comparison is shown in Table IV.

This table amplifies the findings shown in Table III and demonstrates the fact that, when due consideration is given to the presence or absence of a history of rheumatic disease in the parents of 
TABLE IV

Comparison of the relative frequency of rheumatic manifestations in the aunts and uncles of rheumatic index cases on the paternal and maternal sides; according to the history of rheumatic manifestations in the parents of whom they are siblings

\begin{tabular}{|c|c|c|c|c|c|c|c|}
\hline \multirow{3}{*}{ Sibling of } & \multirow{3}{*}{$\begin{array}{c}\text { Relation } \\
\text { to index } \\
\text { case }\end{array}$} & \multicolumn{3}{|c|}{ Paternal } & \multicolumn{3}{|c|}{ Maternal } \\
\hline & & \multirow{2}{*}{$\underset{\text { ber }}{\text { Num- }}$} & \multicolumn{2}{|c|}{ Rheumatic } & \multirow{2}{*}{$\underset{\text { ber }}{\text { Num- }}$} & \multicolumn{2}{|c|}{ Rheumatic } \\
\hline & & & $\underset{\text { ber }}{\text { Num- }}$ & $\begin{array}{l}\text { Per } \\
\text { cent }\end{array}$ & & Num- & $\begin{array}{l}\text { Per } \\
\text { cent }\end{array}$ \\
\hline \multirow{2}{*}{$\begin{array}{l}\text { Rheumatic } \\
\text { parents of } \\
\text { index cases }\end{array}$} & $\begin{array}{l}\text { Uncles } \\
\text { Aunts }\end{array}$ & $\begin{array}{l}23 \\
26\end{array}$ & $\begin{array}{l}1 \\
3\end{array}$ & $\begin{array}{r}4.3 \\
11.5\end{array}$ & $\begin{array}{r}105 \\
95\end{array}$ & $\begin{array}{l}21 \\
25\end{array}$ & $\begin{array}{l}20.0 \\
26.3\end{array}$ \\
\hline & Total & 49 & 4 & 8.0 & 200 & 46 & 23.0 \\
\hline \multirow{2}{*}{$\begin{array}{l}\text { Non-rheumatic } \\
\text { parents of } \\
\text { index cases }\end{array}$} & $\begin{array}{l}\text { Uncles } \\
\text { Aunts }\end{array}$ & $\begin{array}{l}136 \\
146\end{array}$ & $\begin{array}{l}3 \\
6\end{array}$ & $\begin{array}{l}2.2 \\
4.1\end{array}$ & $\begin{array}{l}108 \\
130\end{array}$ & $\begin{array}{l}12 \\
10\end{array}$ & $\begin{array}{r}11.1 \\
7.7\end{array}$ \\
\hline & Total & 282 & 9 & 3.2 & 238 & 22 & 9.2 \\
\hline
\end{tabular}

index cases, a greater proportion of the maternal than of the paternal aunts and uncles is found to be affected. The number of persons falling into each group in this table is not sufficiently large to allow significance to be attached to the individual percentages, but they are consistent in that, in each instance, they show a higher percentage of persons with rheumatic disease among the maternal aunts and uncles than among the corresponding relatives on the paternal side of the family.

This supplements the observation, brought out by Table III, that more rheumatic disease occurred on the maternal than on the paternal side of these families of rheumatic index cases, and indicates that this difference is present whether the parents be rheumatic or non-rheumatic. This fact is worthy of consideration in any attempt to evaluate the hereditary factors in rheumatic disease.

\section{SUMMARY AND CONCLUSIONS}

Facts have been presented relative to the high incidence of rheumatic disease in the families of 96 rheumatic children. The percentage of persons with a rheumatic history, who had parents with a similar history, was found to be consistent in two generations of these families and was 3.7 times as high as was found in a group of control families.

The offspring of the grandparents of the rheumatic and control index cases were studied to see if any relationship was present between the type of mating with respect to rheumatic disease and the percentage of children who were rheumatic. When one or both parents had a history of rheumatic manifestations a greater percentage of the offspring was rheumatic than was found in the offspring of parents who gave no history of rheumatic disease.

The percentage of female offspring of rheumatic mothers who had rheumatic manifestations was found to be almost twice as high as in the male offspring of these mothers.

A greater percentage of persons with rheumatic disease was found among the maternal aunts and uncles than was found among the paternal aunts and uncles of rheumatic index cases.

These findings suggest that hereditary constitution may play a rolle in the predisposition to this disease. The evidence here presented does not, however, exclude the possibility that infection plays an important rôle, and that exposure may be the predominating factor.

\section{BIBLIOGRAPHY}

1. Read, Frances E. M., Ciocco, A., and Taussig, H. B, The frequency of rheumatic manifestations among the siblings, parents, uncles, aunts, and grandparents of rheumatic and control patients. Am. J. Hyg., 1938, 27, 719.

2. Draper, George, Studies in human constitution. IV. Heredity and environment-the disease makers. Am. J. M. Sc., 1926, 171, 803.

3. Irvine-Jones, E., Acute rheumatism as a familial disease. Am. J. Dis. Child., 1933, 45, 1184.

4. Wilson, M. G., and Schweitzer, M. D., Rheumatic fever as a familial disease. Environment, communicability and heredity in their relation to the observed familial incidence of the disease. J. Clin. Invest., 1937, 16, 555. 